\title{
Experimental Investigation of Neutralisation of Concrete with Fly Ash as Fine Aggregate in Freeze-Thaw Environment
}

\author{
Dongsheng Zhang $\left(\mathbb{D},{ }^{1}\right.$ Mingjie Mao $\mathbb{D}^{1,},{ }^{1,2}$ Qiuning Yang $\left(\mathbb{D},{ }^{1,2}\right.$ Wenbo Zhang, ${ }^{1,2}$ \\ and Pengfei Han ${ }^{1}$ \\ ${ }^{1}$ School of Civil and Hydraulic Engineering, Ningxia University, Yinchuan 750021, China \\ ${ }^{2}$ Arid Area Modern Agriculture Water Resources Efficient Utilization Ministry of Education Engineering Research Center, \\ Yinchuan 750021, China
}

Correspondence should be addressed to Mingjie Mao; maomjnxdx@163.com

Received 25 April 2019; Accepted 4 June 2019; Published 25 June 2019

Academic Editor: Arnaud Perrot

Copyright (c) 2019 Dongsheng Zhang et al. This is an open access article distributed under the Creative Commons Attribution License, which permits unrestricted use, distribution, and reproduction in any medium, provided the original work is properly cited.

\begin{abstract}
To study the durability of concrete with fly ash as fine aggregate under alternate freeze-thaw and carbonation, freeze-thaw and carbonation cyclic tests are conducted to explore variation characteristics such as relative dynamic modulus of elasticity and neutralisation depth. The influence coefficient $\left(\lambda_{\mathrm{C}}\right)$ of carbonation on concrete freeze-thaw damage and the influence coefficient $\left(\lambda_{\mathrm{F}}\right)$ of freeze-thaw on concrete neutralisation are introduced. In addition, scanning electron microscopy is performed to reveal the deterioration mechanism of the alternating effect. Finally, through a regression analysis of test data, the mathematical expression of the composite damage coefficient $k_{\mathrm{F}}$ under alternate freeze-thaw and carbonation is obtained. Based on these findings, a prediction model of the neutralisation depth of concrete is established with number of freeze-thaw cycles and water-cement ratio as parameters. The values calculated through this model and the values measured in the tests are highly correlated. This provides a theoretical reference and basis for the analysis of concrete durability in a multifactor environment.
\end{abstract}

\section{Introduction}

Currently, concrete-structure service life prediction has attracted significant attention. It is known that concrete durability is an important consideration in reducing the social cost of new buildings and maintenance of infrastructures [1]. From the perspective of concrete durability, freeze-thaw is a major cost of aging infrastructure that results in concrete deterioration in cold climates. Hence, freeze-thaw is often considered in structural design [2-4]. Meanwhile, concrete neutralisation is closely related to durability, which is a primary cause of steel corrosion [5].

Considerable research has been performed locally and abroad to study concrete in single-factor environments, such as freeze-thaw cycles and carbonation, and significant achievements have been attained. The conclusions and empirical formulas obtained have been widely recognised in academia and extensively applied and verified in practical engineering [2-4, 6-10]. However, in practical engineering, the coexistence of multiple erosion environments or phased superposition of a single factor typically results in the failure of concrete structures. This applies particularly in severely cold areas where freeze-thaw damage, accompanied by the effect of carbonation, is typical [11]. Therefore, in the design of concrete materials, alternate deteriorations caused by multiple factors should be considered. Hitherto, some preliminary and fragmentary studies have been performed to study the combined effect of freeze-thaw and carbonation on ordinary concrete and fly ash concrete [11-15]. Because research into concrete with fly ash as fine aggregate is restricted to the mechanical properties or effect of a single factor [16-20], conclusions of studies under single-factor conditions are limited.

For many years, fly ash was considered as a supplementary cementitious material or a cement replacement material with a proportion of up to $30-40 \%[21,22]$. As a 
byproduct of industrial production, the use of fly ash for solving the challenges of sustainable construction has progressed. However, the positive utilisation of fly ash is impossible when it is used as an alternative cementitious material of cement owing to its early delayed strength development [23]. Hence, a method of replacing fine aggregate with fly ash was proposed [24-30]. Because fly ash replaces part of the fine aggregate, part of the fly ash act as a cementitious material to fill pores and increase the compactness, while the remaining produce a volcanic ash effect, which is attributed to the presence of $\mathrm{SiO}_{2}$ and $\mathrm{Al}_{2} \mathrm{O}_{3}$. It reacts with calcium hydroxide to form additional calcium silicate hydrate $(\mathrm{CSH})$ and calcium aluminate hydrate $(\mathrm{CAH})$, which effectively constitute a compact matrix [31-33]. As such, the early strength of concrete with part of the fine aggregate replaced by fly ash is superior to that of concrete with cement fully replaced by fly ash $[26,28-30]$.

In this study, the durability cyclic test of concrete under the alternation of carbonation and freeze-thaw is conducted. During the test, the relative dynamic modulus of elasticity and neutralisation depth is measured. The results are compared with the measured results under the single effect and alternating effect. In addition, the prediction model of the neutralisation depth of concrete in a freeze-thaw environment is established, which is significant for evaluating the durability of concrete in cold areas.

\section{Materials and Methods}

2.1. Raw Materials. The cement used in this study was ordinary Portland cement P.O 42.5R, which was produced by Ningxia Saima Industry Co., Ltd, with the performance indexes presented in Table 1. Class III fly ash used in this study was produced by the Ningxia Xixia Thermal Power Plant, and the physical and chemical properties are presented in Tables 2 and 3, respectively. Continuous-graded crushed stone $(5-31.5 \mathrm{~mm})$ collected from the town of Zhenbeibao in Ningxia Province was used as coarse aggregate, and natural medium sand (fineness modulus of 2.71) was collected from Zhenbeibao and used as fine aggregate. Tap water was used to mix the materials, and polycarboxylate superplasticizer was used as a chemical additive.

\subsection{Design of Mix Proportion. The water-cement ratios of the} three concrete specimens (S1, S2, and S3) are $0.36,0.42$, and 0.48 , respectively. Table 4 presents the mix proportions of the specimens. Some fine aggregates are substituted by fly ash with the same volume. The unit dosage of fly ash is calculated according to:

$$
M_{\mathrm{FA}}=\frac{M_{\mathrm{s}} \cdot R \cdot \rho_{\mathrm{FA}}}{\rho_{\mathrm{s}}},
$$

where $\rho_{\mathrm{S}}$ and $\rho_{\mathrm{FA}}$ are the densities of fine aggregate and fly ash, respectively; $M_{\mathrm{S}}$ and $M_{\mathrm{FA}}$ are the unit consumptions of fine aggregate and fly ash, respectively [33]; $R$ is the substitution rate of fly ash, which is $15 \%$ in this test.
2.3. Experimental Protocol. The size of the specimens was $100 \mathrm{~mm} \times 100 \mathrm{~mm} \times 400 \mathrm{~mm}$. After being moulded, the specimens were stored under curing with moulds for $24 \mathrm{~h}$. After the moulds were removed, the specimens were cured for 56 days in a curing room.

In real engineering, concrete often experiences alternate seasons of autumn and winter and alternate seasons of winter and spring. Hence, the tests were implemented in four modes:

(1) Alternative freeze-thaw and carbonation (FC mode): (1) Immerse the specimens in water $\left(20 \pm 2^{\circ} \mathrm{C}\right)$ for four days before the test such that they become water saturated. Subsequently, remove them, clean the surface water, and measure their dynamic modulus of elasticity. (2) Clean the surface water of the specimens every 25 freeze-thaw cycles and measure their dynamic modulus of elasticity. (3) When the number of cycles reaches 50 , remove the specimens and air-dry them for one day. (4) Store the specimens in an oven $\left(60^{\circ} \mathrm{C}\right)$ for two days, and subsequently place them in a carbonation chamber to conduct the five-day rapid carbonation test. Finally, remove them to measure their neutralisation depths. This is a complete cyclic process of freeze-thaw and carbonation that will be repeated for six cycles.

(2) Alternative carbonation and freeze-thaw (CF mode): (1) Store the specimens in the oven $\left(60^{\circ} \mathrm{C}\right)$ for two days and conduct the five-day rapid carbonation test. Subsequently, remove them to measure their neutralisation depths. (2) Immerse the specimens in water $\left(20 \pm 2^{\circ} \mathrm{C}\right)$ for four days such that they become water saturated. Subsequently, remove them, clean the surface water, and measure their dynamic modulus of elasticity. (3) Clean the surface water of the specimens every 25 freeze-thaw cycles and measure their dynamic modulus of elasticity. (4) When the number of cycles reaches 50 , remove the specimens and air-dry them for one day. This is a complete cyclic process of carbonation and freezethaw that will be repeated for six cycles.

(3) Single freeze-thaw (F mode): Clean the surface water of the specimens every 25 freeze-thaw cycles and measure their dynamic modulus of elasticity. The complete cyclic process includes 50 cycles of freezethaw that will be repeated for six cycles.

(4) Single carbonation (C mode): Five-day carbonation is a complete cyclic process, and it will be repeated for six cycles. After each five-day carbonation, remove the specimens to measure their neutralisation depths.

Table 5 presents the grouping of the test.

\subsection{Experimental Methods}

2.4.1. Freeze-Thaw Test. In this study, the cyclic freeze-thaw test was conducted in an accelerated freeze-thaw testing apparatus. Concrete samples were immersed in water 
TABle 1: P.O 42.5R ordinary cement indexes.

\begin{tabular}{|c|c|c|c|c|c|c|c|c|c|}
\hline \multicolumn{2}{|c|}{$\begin{array}{l}\text { Cement setting } \\
\text { time (min) }\end{array}$} & \multicolumn{2}{|c|}{$\begin{array}{c}\text { Rupture } \\
\text { strength } \\
(\mathrm{MPa})\end{array}$} & \multicolumn{2}{|c|}{$\begin{array}{c}\text { Compressive } \\
\text { strength } \\
(\mathrm{MPa})\end{array}$} & \multirow{2}{*}{$\begin{array}{c}\text { Fineness } \\
\text { (retained in } 80 \mu \mathrm{m})(\%)\end{array}$} & \multirow{2}{*}{$\begin{array}{l}\text { Ignition } \\
\text { loss (\%) }\end{array}$} & \multirow[t]{2}{*}{$\mathrm{MgO}(\%)$} & \multirow{2}{*}{$\mathrm{SO}_{3}(\%)$} \\
\hline $\begin{array}{l}\text { Initial } \\
\text { time }\end{array}$ & Final time & $3 d$ & $28 \mathrm{~d}$ & $3 d$ & $28 \mathrm{~d}$ & & & & \\
\hline 113 & 153 & 4.7 & 4.8 & 23.1 & 43.6 & 1.6 & 1.4 & 1.54 & 2.96 \\
\hline
\end{tabular}

TABLe 2: Chemical composition of Class III fly ash.

\begin{tabular}{lcccccccc}
\hline $\mathrm{SiO}_{2}$ & $\mathrm{Al}_{2} \mathrm{O}_{3}$ & $\mathrm{CaO}$ & $\mathrm{Fe}_{2} \mathrm{O}_{3}$ & $\mathrm{MgO}$ & $\mathrm{SO}_{3}$ & $\mathrm{P}_{2} \mathrm{O}_{5}$ & $\mathrm{Na}_{2} \mathrm{O}$ & $\mathrm{K}_{2} \mathrm{O}$ \\
\hline 50.35 & 29.65 & 5.85 & 6.61 & 1.83 & 1.72 & 1.13 & 0.335 & 2.11 \\
\hline
\end{tabular}

TABle 3: Physical properties of Class III fly ash.

\begin{tabular}{lc}
\hline Properties & Fly ash \\
\hline Fineness (retained in $80 \mu \mathrm{m})(\%)$ & 34.3 \\
Water demanded $(\%)$ & 97 \\
Loss on ignition $(\%)$ & 5.7 \\
Density $\left(\mathrm{g} / \mathrm{cm}^{3}\right)$ & 2.058 \\
\hline
\end{tabular}

TABLE 4: Mixture proportions for a cubic meter of concrete.

\begin{tabular}{lcccccccc}
\hline $\begin{array}{l}\text { Specimen } \\
\text { code }\end{array}$ & $\begin{array}{c}\text { Water cement } \\
\text { ratio }\end{array}$ & $\begin{array}{c}\text { Water } \\
\left(\mathrm{kg} / \mathrm{m}^{3}\right)\end{array}$ & $\begin{array}{c}\text { Cement } \\
\left(\mathrm{kg} / \mathrm{m}^{3}\right)\end{array}$ & $\begin{array}{c}\text { Fly ash } \\
\left(\mathrm{kg} / \mathrm{m}^{3}\right)\end{array}$ & $\begin{array}{c}\text { Sand } \\
\left(\mathrm{kg} / \mathrm{m}^{3}\right)\end{array}$ & $\begin{array}{c}\text { Gravel } \\
\left(\mathrm{kg} / \mathrm{m}^{3}\right)\end{array}$ & $\begin{array}{c}\text { Superplasticizer } \\
\left(\mathrm{kg} / \mathrm{m}^{3}\right)\end{array}$ & $\begin{array}{c}\text { Compressive strength } \\
(56 \mathrm{~d})(\mathrm{MPa})\end{array}$ \\
\hline S1 & 0.36 & 185 & 514 & 80 & 569 & 1003 & 13.0 & 53.4 \\
S2 & 0.42 & 185 & 440 & 85 & 608 & 1030 & 10.5 & 49.4 \\
S3 & 0.48 & 185 & 385 & 90 & 643 & 1045 & 7.1 & 42.1 \\
\hline
\end{tabular}

TABLE 5: Grouping of the test.

\begin{tabular}{lccc}
\hline Test mode & \multicolumn{2}{c}{ Test program } & \\
\hline Freeze-thaw and carbonation (FC) & Freeze-thaw cycle 50 times & $60^{\circ} \mathrm{C}$, dry for 2 d & Carbonation environment $5 \mathrm{~d}$ \\
Carbonation and freeze-thaw (CF) & Carbonation environment $5 \mathrm{~d}$ & Tap water, immerse for $4 \mathrm{~d}$ & Freeze-thaw cycle 50 times \\
Single freeze-thaw (F) & Freeze-thaw cycle 50 times & \\
Single carbonation (C) & \multicolumn{2}{c}{ Carbonation environment $5 \mathrm{~d}$} & \\
\hline
\end{tabular}

$\left(20 \pm 2^{\circ} \mathrm{C}\right)$ for four days before the test such that the samples become water saturated. The samples were removed from the apparatus, surface water was removed, and their dynamic modulus of elasticity was measured. Subsequently, the samples in the freeze-thaw chamber and the temperature in the concrete centres were controlled between $(-18 \pm 2)^{\circ} \mathrm{C}$ and $(5 \pm 2)^{\circ} \mathrm{C}$. Every time the number of freeze-thaw cycles reached 25 or a multiple of 25 , we wiped off the surface water of the samples and measured their dynamic modulus of elasticity.

2.4.2. Carbonation Test. A rapid carbonation test was performed. The prepared samples were placed in an oven (interior temperature of $60^{\circ} \mathrm{C}$ ) and dried for $48 \mathrm{~h}$. Subsequently, we sealed the five sides of all samples (not including the tops) with paraffin. Next, we placed the samples into the carbonation chamber; the spaces between them were no less than $50 \mathrm{~mm}$. When the carbonation progressed to 5 ,
$10,15,20,25$, and $30 \mathrm{~d}$, we removed the samples to measure their carbonation depths.

2.4.3. Scanning Electron Microscopy. Scanning electron microscopy analysis of S2 samples before the test and after a 30-day carbonation in different test modes was performed using the Quanta 400 FEG scanning electron microscope.

\section{Results}

3.1. Relative Dynamic Modulus of Elasticity. The relative dynamic modulus of elasticity (RDME) is an important parameter of concrete freeze-thaw damage [34]. To compare the RDME in different modes, the freeze-thaw damage degree $(D)$ is introduced, which is expressed as follows:

$$
D(N)=1-\frac{E(N)}{E_{0}}
$$


where $D(N)$ is the damage degree of concrete after $N$ freezethaw cycles, $E(N)$ is the RDME of concrete after $N$ freezethaw cycles, and $E_{0}$ is the initial RDME of concrete.

In FC and F modes, the difference in the degree of freezethaw damage is

$$
\Delta D_{\mathrm{FC}}(N)=D_{\mathrm{FC}}(N)-D_{\mathrm{F}}(N) .
$$

In $\mathrm{CF}$ and $\mathrm{F}$ modes, the difference in the degree of freezethaw damage is

$$
\Delta D_{\mathrm{CF}}(N)=D_{\mathrm{CF}}(N)-D_{\mathrm{F}}(N) .
$$

The relation between RDME and the number of cycles in the FC mode is presented in Figure 1, and the RDMEs in different modes (water-cement ratio of 0.42 ) are presented in Figure 2. The changes in the degree of freeze-thaw damage with the number of cycles are presented in Figure 3.

As shown in Figure 1, the RDME of concrete is negatively correlated with the number of cycles. After 300 freezethaw cycles, with a water-cement ratio of 0.48 , the RDME is the lowest at 0.838 . With a water-cement ratio of 0.42 , the RDME becomes 0.873 ; with a water-cement ratio of 0.36 , the value is the highest at 0.904 . All the RDME values of concrete after 300 freeze-thaw cycles are above 0.6 ; this suggests that the concrete exhibits better freeze-thaw resistance than ordinary concrete [35].

As shown in Figures 2 and 3, when the number of cycles is less than 300, the freeze-thaw damage in the FC and CF modes is more severe than the damage in the F mode, with the FC mode affecting the freeze-thaw damage to a greater extent than the CF mode. This is because in a freeze-thaw environment, the structure of concrete changes gradually from compact to porous and full of microcracks $[36,37]$. In a rapid carbonation environment, permeable $\mathrm{CO}_{2}$ will interact with $\mathrm{Ca}(\mathrm{OH})_{2}$ in concrete to cause a neutralisation reaction, through which acid salt $\mathrm{CaCO}_{3}$ is generated to fill the internal structural pores and serve as grouting. Hence, the porosity is reduced temporarily [38] and the loss rate of RDME is temporarily relieved. However, this is a vicious cycle. That is, freeze-thaw causes a greater damage effect on concrete than carbonation. With the increase in the watercement ratio and number of cycles, the extent of the vicious circle becomes increasingly worse. Meanwhile, in terms of structural damage to concrete, during carbonation, permeable $\mathrm{CO}_{2}$ interacts with $\mathrm{Ca}(\mathrm{OH})_{2}$ in concrete to cause a neutralisation reaction, and the generated $\mathrm{CaCO}_{3}$ can fill the internal pores to temporarily improve the internal porosity and relieve the loss rate of RDME [39]. This suggests that the carbonation reaction can inhibit the expansion of freezethaw degradation characteristics.

3.2. Change Law of Neutralisation Depth. To analyse the change law of the neutralisation depth of concrete in a complex environment, the relation between neutralisation depth and time in the FC mode at different water-cement ratios was studied, and the results are shown in Figure 4. The relation between neutralisation depth and time in different test modes is presented in Figure 5. The carbonation rate is controlled by diffusion, and the diffusion coefficient of

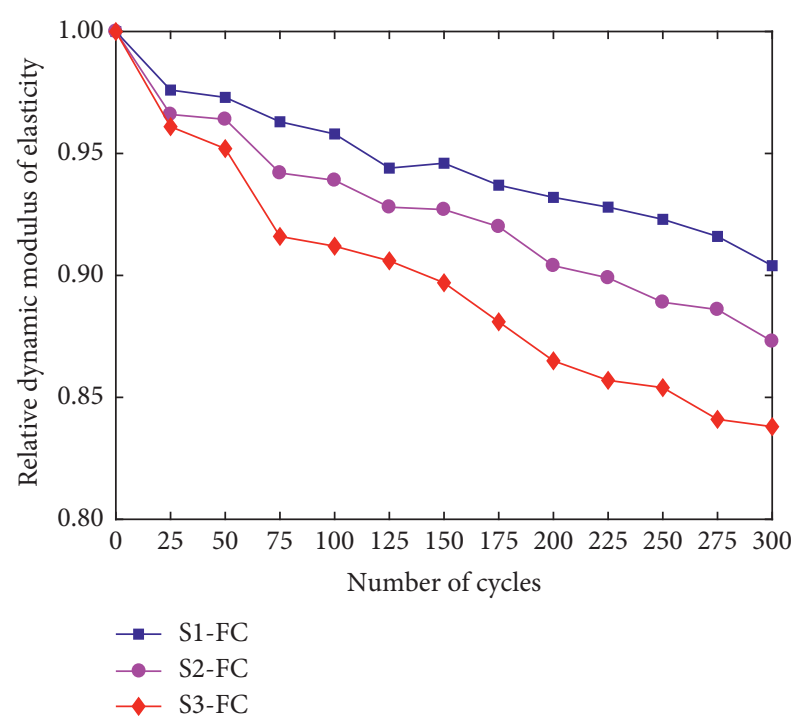

FIGURE 1: Relative dynamic modulus of elasticity of S1, S2, and S3 in FC mode. S2 in different testing modes.

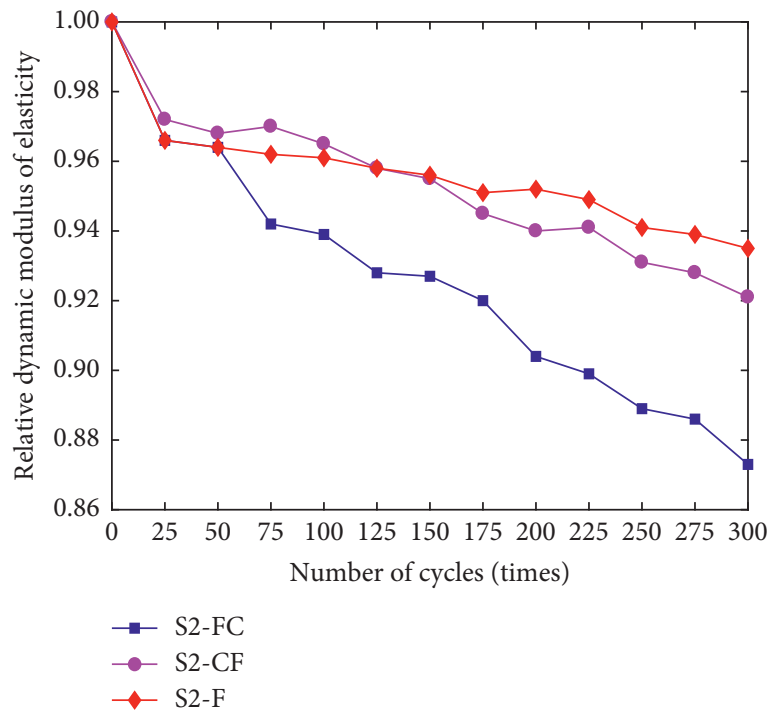

FIgURE 2: Relative dynamic modulus of elasticity of S2 in different testing modes.

carbon dioxide in carbonated concrete is a characteristic transport coefficient [40]. Assuming a constant diffusion coefficient for the carbonated layer, the depth of carbonation can be derived from Fick's first law of diffusion [41]:

$$
X_{\mathrm{c}}=K \sqrt{t},
$$

where $X_{\mathrm{c}}$ is the depth of carbonation, $t$ is the carbonation time, and $K$ is the carbonation velocity coefficient. Using test data, the carbonation velocity coefficient $K$ of group S2 specimen can be obtained from equation (5), as shown in Figure 6.

As shown in Figure 4, in the coupling test mode of freeze-thaw and carbonation, the neutralisation depth is positively correlated with the water-cement ratio under different strength conditions [30]. As shown in Figures 5 and 6 , in the three test modes, the neutralisation depth is 


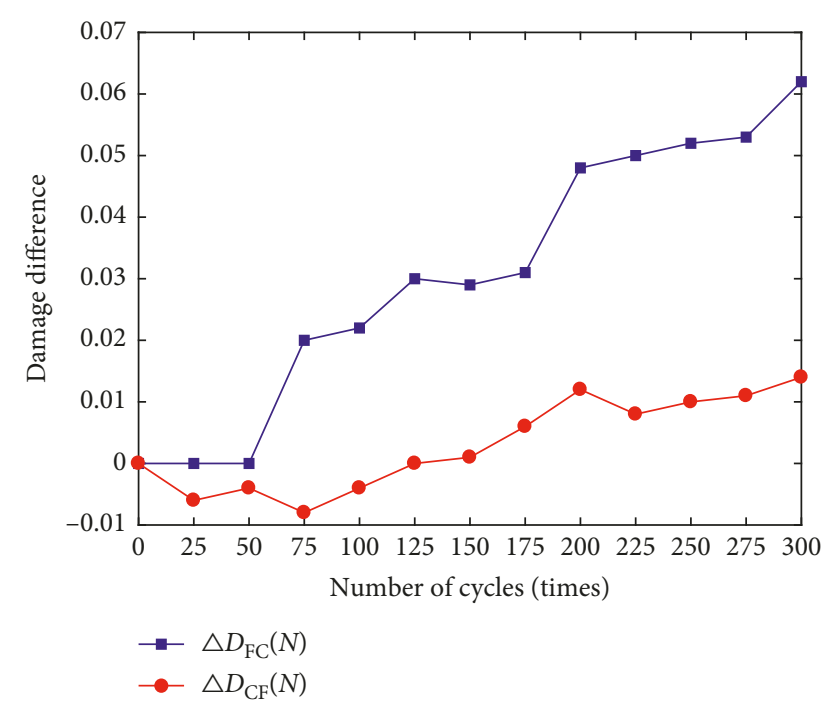

FIGURE 3: Damage difference of S2 between different testing modes.

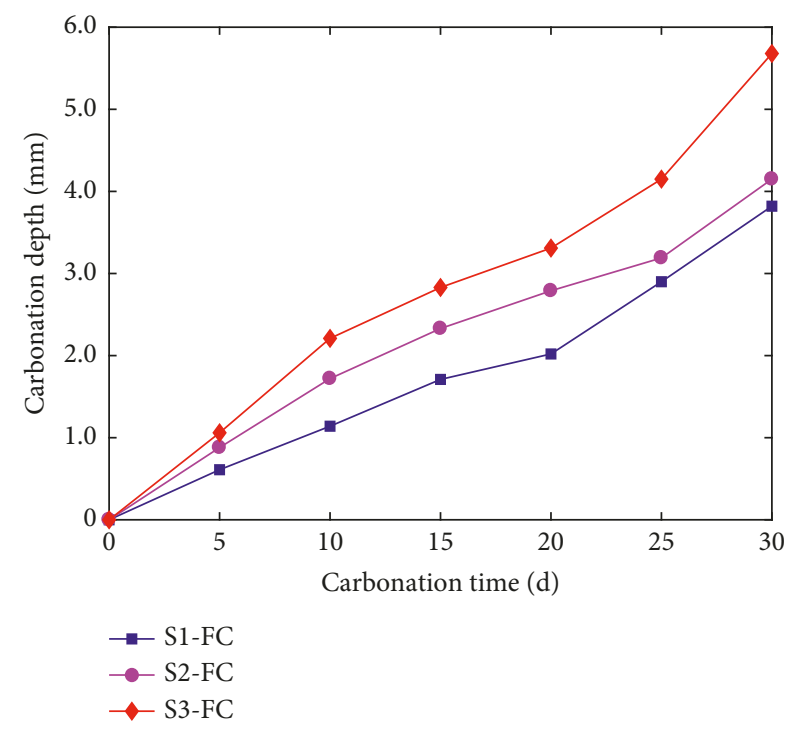

FIgURE 4: Carbonation depths of S1, S2, and S3 in FC mode.

positively correlated with carbonation time, thus implying that the neutralisation depth increases gradually with prolonged carbonation time. At the same carbonation time, the neutralisation depths and carbonation velocity coefficient in both FC and CF modes are greater than that in the $\mathrm{C}$ mode. After carbonation for 20 days, the carbonation velocity coefficient of concrete in the $\mathrm{C}$ mode is relatively flat compared to those in the FC and CF modes. This is because the alternating effect accelerates the development and connection of microcracks on the surface of concrete, thus facilitating the diffusion of $\mathrm{CO}_{2}$ into the concrete interior and promotes concrete neutralisation. In addition, the freeze-thaw environment is a catalyst for accelerating the carbonation corrosion of concrete [33]. It can be observed that the neutralisation depth in the FC mode is greater than that in the CF mode. This is because when the concrete is first exposed to carbonation, the carbonised products fill the

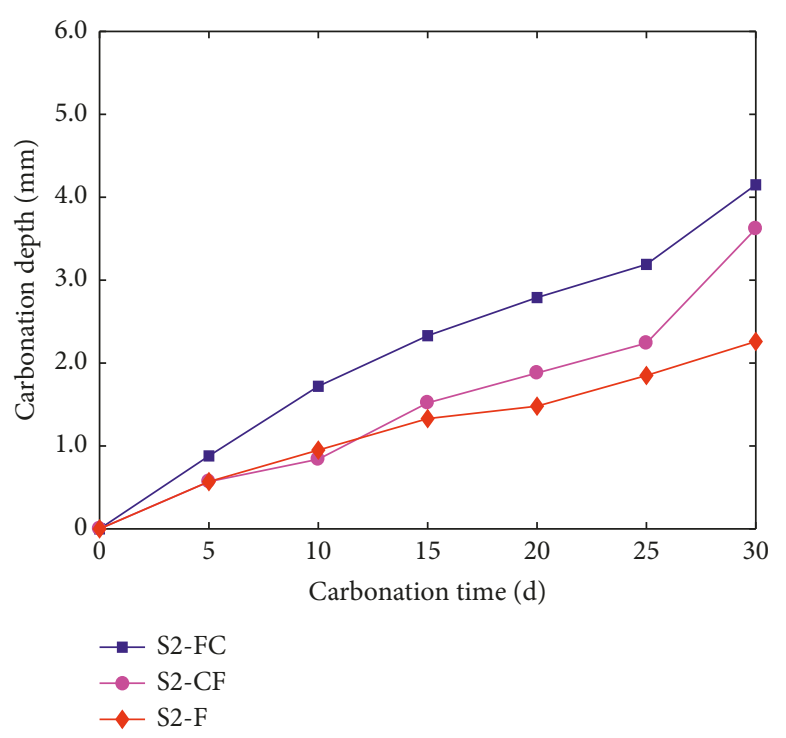

Figure 5: Carbonation depth of S2 in different testing modes.

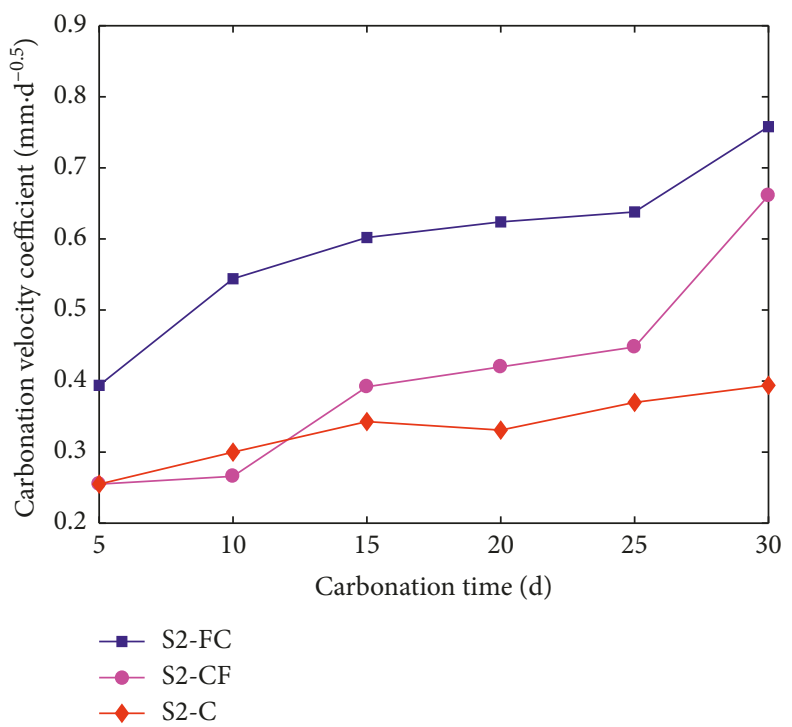

FIgURE 6: Carbonation velocity coefficient of $\mathrm{S} 2$ in different testing modes.

internal voids of concrete, thus enhancing the compactness of concrete [5]. However, if the concrete is first exposed to freeze-thaw, the freezing effect generates many microcracks in the concrete and causes surface cracking and even peeling [42]. Micropores and microcracks can accelerate the diffusion of $\mathrm{CO}_{2}$ in the internal structure and improve the neutralisation depth. The increase in neutralisation depth is faster with the increase in freeze-thaw cycles.

\subsection{Analysis of Interaction between Freeze-Thaw Cycle and Carbonation}

3.3.1. Analysis of Carbonation on Freeze-Thaw Damage. The degree of concrete damage is studied by analysing the RDME of concrete under the alternating effect. The 
influence coefficient $\left(\lambda_{\mathrm{C}}\right)$ of carbonation on the freeze-thaw damage of concrete is introduced and defined as follows [43]:

$$
\lambda_{\mathrm{C}}=\frac{D_{\mathrm{F}+\mathrm{C}}}{D_{\mathrm{F}}},
$$

where $D_{\mathrm{F}+\mathrm{C}}$ is the composite damage degree of the concrete under the alternating effect and $D_{\mathrm{F}}$ is the damage degree of the concrete under the single effect of freeze-thaw cycles.

If $\lambda_{\mathrm{C}}=1$, it indicates that carbonation does not affect concrete damage. If $\lambda_{\mathrm{C}}<1$, it indicates that carbonation presents an inhibiting effect on concrete damage. If $\lambda_{\mathrm{C}}>1$, it indicates that carbonation presents an acceleration effect on concrete damage, and the greater the value, the stronger the acceleration effect. The calculation results of the influence coefficient $\left(\lambda_{\mathrm{C}}\right)$ are presented in Table 6.

As shown in Table 6, in the FC mode, no carbonation occurs in the first 50 freeze-thaw cycles. Therefore, if $\lambda_{C}=1$, it indicates that carbonation does not affect concrete damage. After 50 freeze-thaw cycles, the values of $\lambda_{\mathrm{C}}$ are all greater than 1 , indicating that carbonation presents an acceleration effect on concrete damage, and the acceleration effect becomes more prominent with more cycles. In general, the greater the water-cement ratio, the greater the influence coefficient $\left(\lambda_{\mathrm{C}}\right)$. In the CF mode, during the first 100-125 freeze-thaw cycles, the values of $\lambda_{\mathrm{C}}$ are all less than 1 , indicating that when carbonation is first exerted on concrete, the compactness of the concrete structure is enhanced and the freeze-thaw damage of the concrete is inhibited [44]. Subsequently, if the values of $\lambda_{\mathrm{C}}$ are still larger than 1 , it indicates that in the early stage of the alternate action, carbonation can prevent the decay of the pore structure caused by partial freeze-thaw, which is beneficial in improving the frost resistance durability of concrete. However, with extended alternate periods, carbonation will accelerate the freeze-thaw damage of concrete.

3.3.2. Influence Coefficient of the Freeze-Thaw Cycle on the Development of Concrete Neutralisation Depth. The effect of the freeze-thaw cycle on concrete carbonation is analysed by studying the neutralisation depth under alternate freezethaw cycles and carbonation as well as the test results of neutralisation depth in the single carbonation mode. The influence coefficient $\left(\lambda_{\mathrm{F}}\right)$ of the freeze-thaw cycle on the neutralisation depth of the concrete is introduced, which is expressed as follows [13]:

$$
\lambda_{\mathrm{F}}=\frac{x_{\mathrm{F}+\mathrm{C}}}{x_{\mathrm{C}}},
$$

where $x_{\mathrm{F}+\mathrm{C}}$ is the neutralisation depth $(\mathrm{mm})$ under the alternating effect, and $x_{\mathrm{c}}$ is the neutralisation depth $(\mathrm{mm})$ under single carbonation.

If $\lambda_{\mathrm{F}}=1$, it indicates that the freeze-thaw cycle does not affect concrete neutralisation. If $\lambda_{\mathrm{F}}<1$, it indicates that the freeze-thaw inhibits the neutralisation to some extent. If $\lambda_{\mathrm{F}}>1$, it indicates that the freeze-thaw cycle accelerates concrete neutralisation, and the acceleration effect becomes more prominent with more cycles [43]. The calculation results of $\lambda_{\mathrm{F}}$ in different test modes are presented in Table 7.

As shown in Table 7, in the FC mode, the influence coefficient $\lambda_{\mathrm{F}}$ increases progressively and is always greater than 1, indicating that when freeze-thaw is first exerted on concrete, it accelerates concrete neutralisation and the acceleration effect becomes more prominent with prolonged time. In the CF mode, the influence coefficient $\lambda_{\mathrm{F}}$ increases gradually. However, unlike CF mode, freeze-thaw affects concrete neutralisation except for the first five days of carbonation when concrete is not subjected to freeze-thaw. In the first 10 days of carbonation, the influence coefficient $\lambda_{\mathrm{F}}$ still remains below 1 , indicating that in the early stages of the test, the freeze-thaw cycle inhibits neutralisation, whereas it accelerates neutralisation over time.

3.4. Scanning Electron Microscopy (SEM). As an inhomogeneous porous material, the inherent defects in concrete can become a weak link for harmful substances, such as $\mathrm{CO}_{2}$, entering the interior of the concrete. A microstructure analysis technique (SEM) was used to test the concrete of group S2 to reveal the deterioration mechanism of concrete under the alternating effect.

Figure 7 shows the microstructure of the concrete of group S2 before the test and after 30 days of carbonation in different test modes. The hydration process of concrete mixed with fly ash is as follows: First, cement clinker hydration precipitates $\mathrm{Ca}(\mathrm{OH})_{2}$ diffuse to the surface of fly ash spherical vitreous bodies through liquid phase diffusion [45]. Subsequently, chemisorption and erosion occur, producing $\mathrm{Ca}(\mathrm{OH})_{2}$, ettringite (AFt), and $\mathrm{CSH}$ gel randomly. As shown in Figure 7(a), most hydration products start to appear in gelatinous form, and a large number of hydrated calcium silicate fibrous crystals are generated on the surface of fly ash particles, which are cross connected to each other to form a high bond strength. As shown in Figure 7(b), the $\mathrm{CaCO}_{3}$ generated by the reaction between the $\mathrm{CSH}$ gel and $\mathrm{CO}_{2}$ gas is cross filled in the internal pores and microcracks and deposited on the surface of pores [46, 47]. The large internal pore size of concrete no longer exists, while the number and density of small pores increase. As shown in Figures 7(c) and $7(d)$, cracks appear on the surface of the concrete samples under the CF mode, but they do not interconnect with each other. The hydration products are loose and light flocculent. The failure of concrete is the most obvious in the FC test mode. The concrete sample surface microcracks are densely distributed and intersect with each other, and the hydration products are loose. Through comparison, it was found that carbonation facilitates in resisting freeze-thaw; however, freeze-thaw is generally more significant, which accelerates the occurrence of carbonation.

\section{Prediction Model of Neutralisation Depth of Concrete in Freeze-Thaw Environment}

Currently, two primary types of prediction models of the neutralisation depth of concrete exist: (1) The theoretical 
TABLE 6: Calculation results of the influence coefficient $\left(\lambda_{\mathrm{C}}\right)$.

\begin{tabular}{|c|c|c|c|c|c|c|c|c|c|c|c|c|}
\hline Freeze-thaw cycle times & 25 & 50 & 75 & 100 & 125 & 150 & 175 & 200 & 225 & 250 & 275 & 300 \\
\hline S1-FC & 1.00 & 1.00 & 1.23 & 1.35 & 1.75 & 1.50 & 1.70 & 1.62 & 1.53 & 1.51 & 1.56 & 1.60 \\
\hline S2-FC & 1.00 & 1.00 & 1.53 & 1.56 & 1.71 & 1.66 & 1.63 & 2.00 & 1.98 & 1.88 & 1.87 & 1.95 \\
\hline S3-FC & 1.00 & 1.00 & 1.62 & 1.54 & 1.64 & 1.72 & 1.95 & 2.05 & 1.99 & 1.92 & 1.85 & 1.98 \\
\hline S1-CF & 0.79 & 0.85 & 0.87 & 1.00 & 1.13 & 1.11 & 1.27 & 1.21 & 1.17 & 1.14 & 1.11 & 1.12 \\
\hline S2-CF & 0.82 & 0.89 & 0.79 & 0.90 & 1.00 & 1.02 & 1.12 & 1.25 & 1.16 & 1.17 & 1.18 & 1.22 \\
\hline S3-CF & 0.87 & 0.75 & 0.83 & 0.88 & 1.25 & 1.28 & 1.36 & 1.33 & 1.24 & 1.25 & 1.13 & 1.33 \\
\hline
\end{tabular}

TABLE 7: Calculation results of the influence coefficient $\left(\lambda_{\mathrm{F}}\right)$.

\begin{tabular}{|c|c|c|c|c|c|c|}
\hline Carbonation time $(\mathrm{d})$ & 5 & 10 & 15 & 20 & 25 & 30 \\
\hline S1-FC & 1.61 & 1.50 & 1.88 & 2.04 & 2.44 & 2.60 \\
\hline S2-FC & 1.54 & 1.81 & 1.75 & 1.89 & 1.72 & 1.92 \\
\hline S3-FC & 1.58 & 1.65 & 1.58 & 1.65 & 1.76 & 1.88 \\
\hline S1-CF & 1.00 & 0.77 & 1.11 & 1.33 & 1.48 & 1.65 \\
\hline S2-CF & 1.00 & 0.88 & 1.14 & 1.27 & 1.21 & 1.68 \\
\hline S3-CF & 1.00 & 0.86 & 1.04 & 1.16 & 1.32 & 1.58 \\
\hline
\end{tabular}

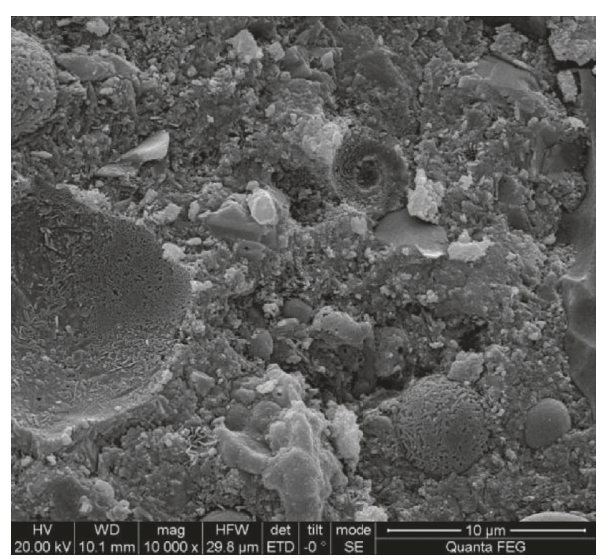

(a)

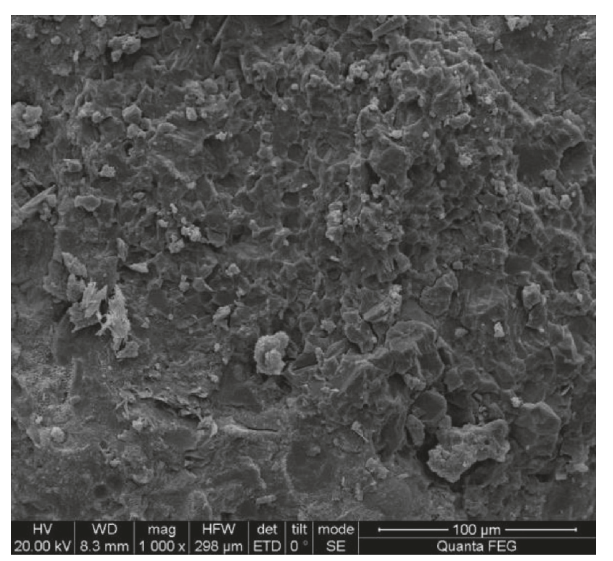

(c)

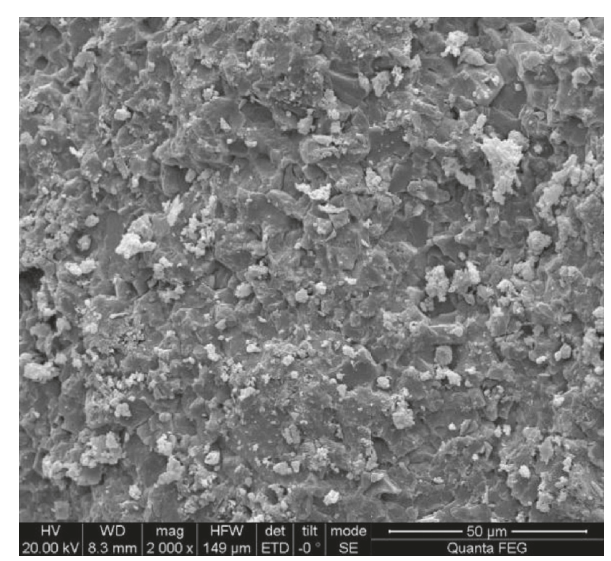

(b)

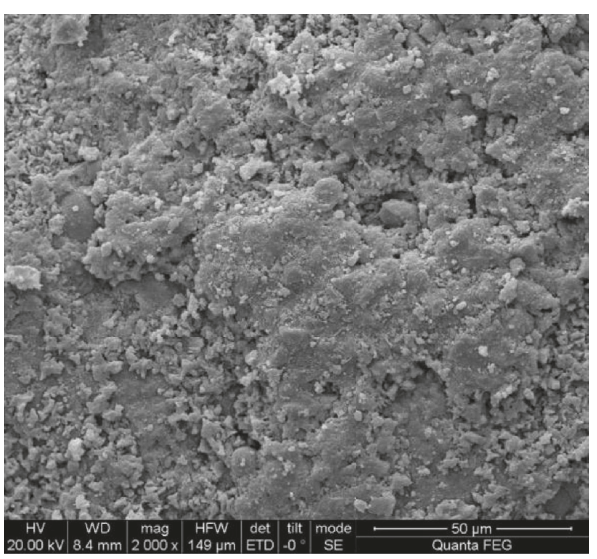

(d)

FiguRE 7: SEM of group S2 samples before test and after 30-day carbonation in different test modes. (a) S2, (b) S2-C, (c) S2-CF, and (d) S2-FC.

model: Papadakis et al. [48] developed an analytical model according to the mass balance conditions of $\mathrm{CO}_{2}$ and carbonised substances during neutralisation. Yu and Jiang
[49] proposed a practical mathematical model of the neutralisation depth of concrete based on the carbonation mechanism. (2) Empirical model: As different factors that 
affect carbonation are considered by different scholars, a variety of prediction models of neutralisation depth have been developed in accordance with actual engineering data or the results of rapid carbonation testing [50-52].

4.1. New Models. The abovementioned models were established in a typical atmosphere environment; therefore, they cannot be applied directly to the freeze-thaw environment. Herein, based on the carbonation mechanism and considering factors such as environmental temperature, relative humidity, $\mathrm{CO}_{2}$ concentration, indoor and outdoor concrete, water-cement ratio, and number of freeze-thaw cycles, the following prediction model is proposed [53]:

$$
x=k_{\mathrm{W}} k_{\mathrm{co}_{2}} k_{\mathrm{T}} k_{\mathrm{RH}} k_{\mathrm{F}} \sqrt{t},
$$

where $k_{\mathrm{W}}$ is the indoor and outdoor influence coefficient of concrete; $k_{\mathrm{CO}_{2}}$ is the influence coefficient of $\mathrm{CO}_{2}$ concentration; $k_{\mathrm{T}}$ is the influence coefficient of environmental temperature; $k_{\mathrm{RH}}$ is the influence coefficient of relative humidity; and $k_{\mathrm{F}}$ is the composite damage coefficient under alternate freeze-thaw and carbonation.

To obtain the composite damage coefficient under the alternating effect, the test data in FC and CF modes were analysed. Subsequently, based on the positive correlation between the neutralisation depth and square root of carbonation time, the neutralisation depths measured in the test are converted into the carbonation coefficient. Using equation (5), the calculation results of the composite damage coefficient $k_{\mathrm{F}}$ in the FC mode are presented in Table 8 , and the calculation results of $k_{\mathrm{F}}$ in the CF mode are presented in Table 9.

The calculation model with the number of freeze-thaw cycles $(N)$ and water-cement ratio $(\mathrm{w} / \mathrm{c})$ as parameters can be obtained through a fitting analysis of $\mathrm{kF}$ in Tables 8 and 9: In FC mode,

$$
\begin{aligned}
k_{\mathrm{F}}= & 1.8479+0.0107 N-7.0790 \times 10^{-5} N^{2} \\
& +1.9460 \times 10^{-7} N^{3}-1.5444 \times 10^{-10} N^{4} \\
& +3.2691 \ln \left(\frac{w}{c}\right)+1.2978 \ln \left(\frac{w}{c}\right)^{2}, \quad N \leq 300 .
\end{aligned}
$$

In FC mode,

$$
\begin{aligned}
k_{\mathrm{F}}= & 1.3780+2.424310^{-4} N+3.7237 \times 10^{-5} N^{2} \\
& -2.8380 \times 10^{-7} N^{3}+6.6222 \times 10^{-10} N^{4} \\
& +0.5560 \ln \left(\frac{w}{c}\right)+1.7954 \ln \left(\frac{w}{c}\right)^{2}, \quad N \leq 250 .
\end{aligned}
$$

Comparisons of the values calculated in the model and those measured in the test are shown in Figures 8 and 9.

The comparison of the measured values and calculated values using formulas (9) and (10) shows that their standard deviation is 0.072 and the correlation coefficient is 0.934 ,
TABLE 8: Calculated values of $k_{\mathrm{F}}$ in FC mode.

\begin{tabular}{lccc}
\hline Number & Number of cycles $(N)$ & Water cement ratio $(\mathrm{w} / \mathrm{c})$ & $k_{\mathrm{F}}$ \\
\hline S1-FC & 50 & 0.36 & 0.272 \\
S2-FC & 50 & 0.42 & 0.394 \\
S3-FC & 50 & 0.48 & 0.474 \\
S1-FC & 100 & 0.36 & 0.361 \\
S2-FC & 100 & 0.42 & 0.544 \\
S3-FC & 100 & 0.48 & 0.699 \\
S1-FC & 150 & 0.36 & 0.442 \\
S2-FC & 150 & 0.42 & 0.602 \\
S3-FC & 150 & 0.48 & 0.731 \\
S1-FC & 200 & 0.36 & 0.452 \\
S2-FC & 200 & 0.42 & 0.624 \\
S3-FC & 200 & 0.48 & 0.740 \\
S1-FC & 250 & 0.36 & 0.580 \\
S2-FC & 250 & 0.42 & 0.638 \\
S3-FC & 250 & 0.48 & 0.830 \\
S1-FC & 300 & 0.36 & 0.697 \\
S2-FC & 300 & 0.42 & 0.758 \\
S3-FC & 300 & 0.48 & 1.040 \\
\hline
\end{tabular}

TABle 9: Calculated values of $k_{\mathrm{F}}$ in CF mode.

\begin{tabular}{lccc}
\hline Number & Number of cycles $(N)$ & Water cement ratio $(\mathrm{w} / \mathrm{c})$ & $k_{\mathrm{F}}$ \\
\hline S1-CF & 0 & 0.36 & 0.170 \\
S2-CF & 0 & 0.42 & 0.255 \\
S3-CF & 0 & 0.48 & 0.300 \\
S1-CF & 50 & 0.36 & 0.231 \\
S2-CF & 50 & 0.42 & 0.266 \\
S3-CF & 50 & 0.48 & 0.364 \\
S1-CF & 100 & 0.36 & 0.261 \\
S2-CF & 100 & 0.42 & 0.392 \\
S3-CF & 100 & 0.48 & 0.483 \\
S1-CF & 150 & 0.36 & 0.295 \\
S2-CF & 150 & 0.42 & 0.420 \\
S3-CF & 150 & 0.48 & 0.523 \\
S1-CF & 200 & 0.36 & 0.352 \\
S2-CF & 200 & 0.42 & 0.448 \\
S3-CF & 200 & 0.48 & 0.624 \\
S1-CF & 250 & 0.36 & 0.444 \\
S2-CF & 250 & 0.42 & 0.661 \\
S3-CF & 250 & 0.48 & 0.873 \\
\hline
\end{tabular}

suggesting good correlation. Therefore, the composite damage coefficient $k_{\mathrm{F}}$ proposed herein is reasonable.

\section{Conclusions}

Freeze-thaw cycle and carbonation were primary causes of concrete damage in cold areas, both of which could reduce the durability of concrete structures and affect the service life of buildings. Based on concrete durability under alternate freeze-thaw cycle and carbonation, the laws of RDME and concrete neutralisation were investigated. Conclusions drawn are as follows:

(1) In the early stage, carbonation was beneficial to concrete's frost resistance; however, over time, it accelerated the rate of freeze-thaw damage. Concrete 


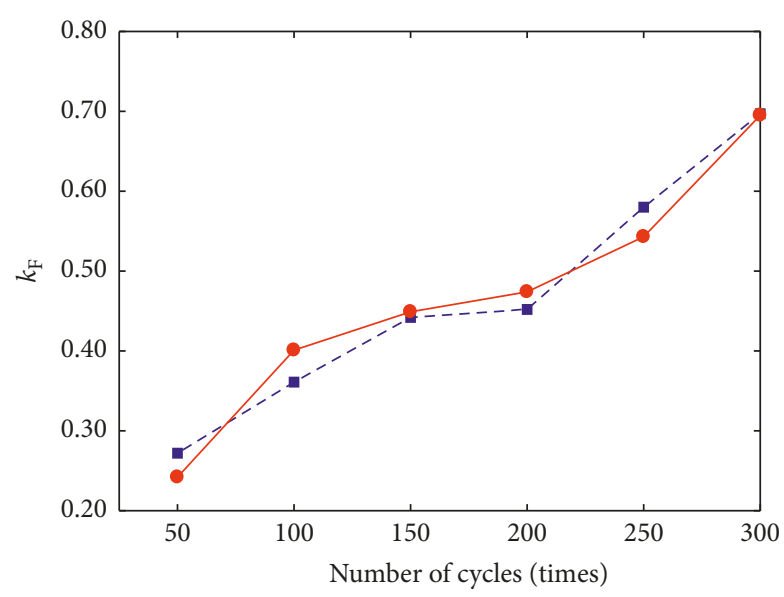

- - Measured value

- Calculated value

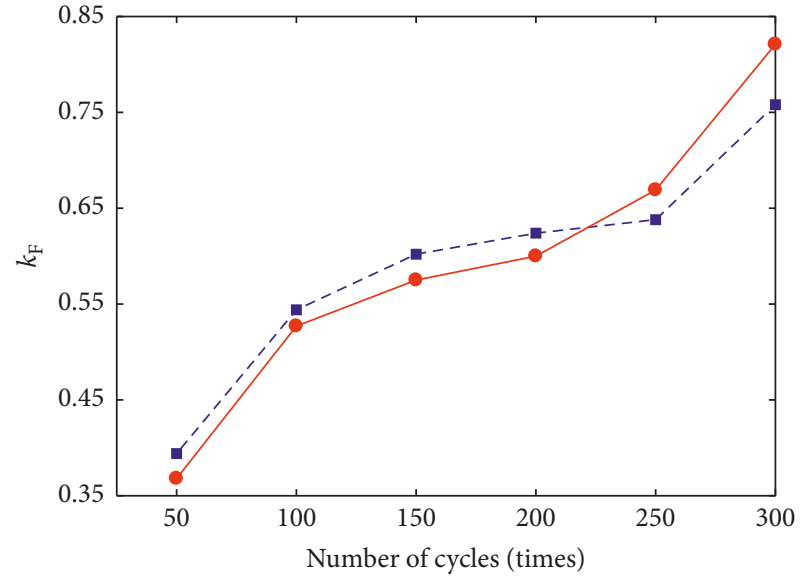

- - Measured value

$\rightarrow$ Calculated value

(a)

(b)

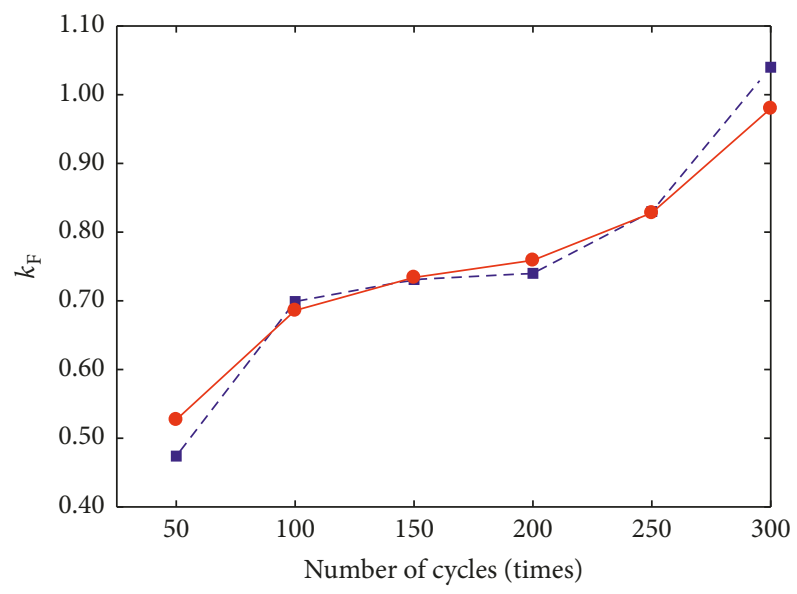

- - Measured value

-- Calculated value

(c)

FIGURE 8: Comparison of measured value and calculated value of the composite damage coefficient $k_{\mathrm{F}}$ in FC mode. (a) S1-FC, (b) S2-FC, and (c) S3-FC.

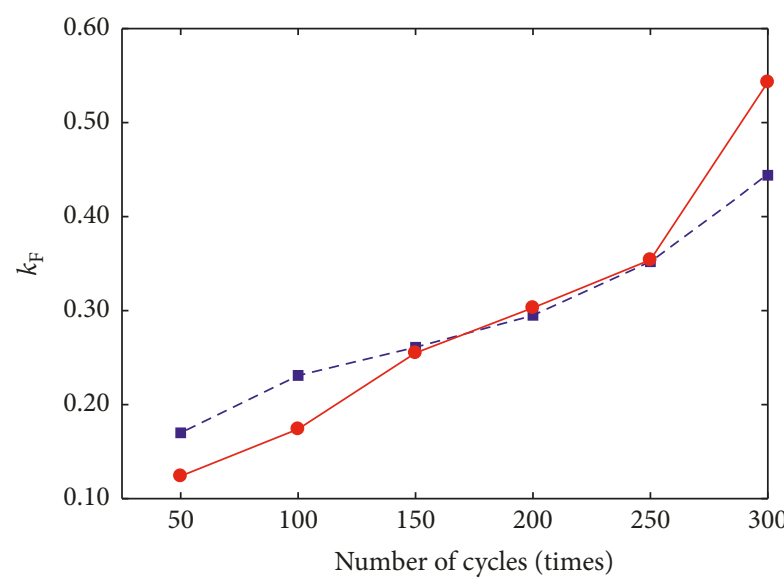

- Measured value

- - Calculated value

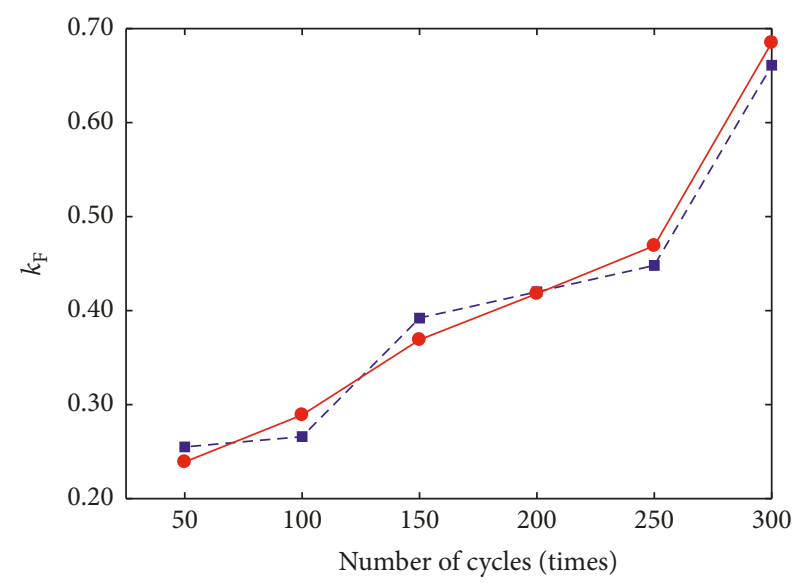

- - Measured value

$\rightarrow$ Calculated value

Figure 9: Continued. 


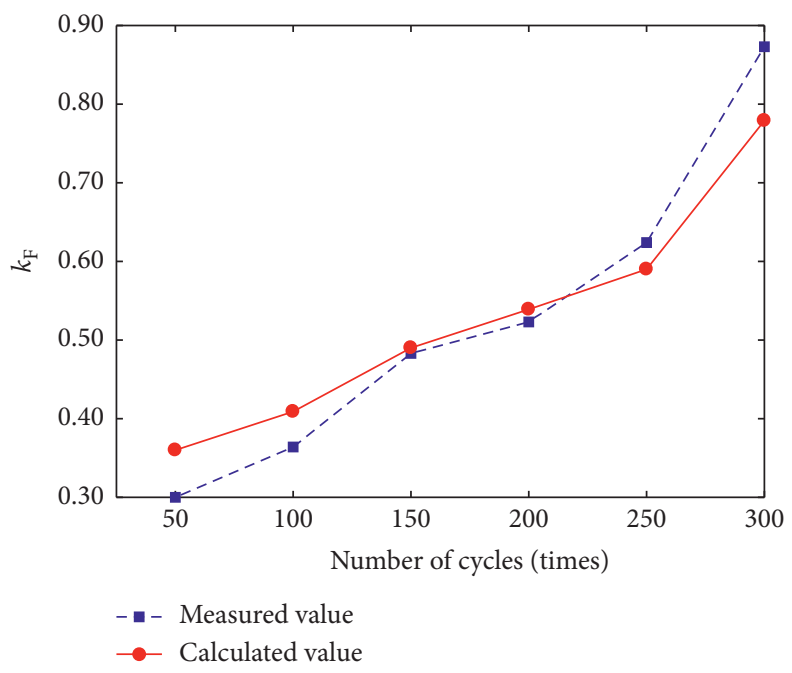

(c)

Figure 9: Comparison of measured value and calculated value of composite damage coefficient $k_{\mathrm{F}}$ in CF mode. (a) S1-CF, (b) S2-CF, and (c) S3-CF.

freeze-thaw damage under the FC mode was more severe than that under the F mode. When an obvious alternating effect occurred in the actual environment, it was insufficient to consider only the single factor of the freeze-thaw cycle in the design of freezethaw durability; alternate freeze-thaw and carbonation must be considered and introduced as well.

(2) Under alternate freeze-thaw and carbonation, regardless of which factor was first applied to concrete, be it freeze-thaw cycle or carbonation, the RDME was lower than that of concrete in the F mode. In the FC mode, concrete exhibited the maximum deterioration at the start of the initial freeze-thaw cycle.

(3) The influence coefficient $\left(\lambda_{\mathrm{C}}\right)$ of carbonation on freeze-thaw damage was introduced to analyse the effect of carbonation on the freeze-thaw damage of concrete. The influence coefficient $\left(\lambda_{\mathrm{F}}\right)$ of freezethaw on concrete neutralisation was introduced to analyse the effect of the freeze-thaw cycle on the neutralisation depth of concrete.

(4) Through a regression analysis of test data, the mathematical expression of the composite damage coefficient $k_{\mathrm{F}}$ under alternate freeze-thaw and carbonation was presented. In addition, based on the analysis of influence factors of concrete neutralisation in the freeze-thaw environment, the prediction model of the neutralisation depth of concrete was established and its fitting precision was verified to be high.

\section{Data Availability}

The data used to support the findings of this study are available from the corresponding author upon request.

\section{Conflicts of Interest}

The authors declare that they have no conflicts of interest.

\section{Acknowledgments}

This study was supported by the National Natural Science Foundation of China (51568055), the Special Projects for Scientific and Technological Cooperation with Foreign Countries of Ningxia Province of China (2018BFH03002), and the Postgraduate Innovation Project of Ningxia University. Their results were fundamental to this study.

\section{References}

[1] J. Marchand and E. Samson, "Predicting the service-life of concrete structures-limitations of simplified models," $\mathrm{Ce}$ ment and Concrete Composites, vol. 31, no. 8, pp. 515-521, 2009.

[2] A. Richardson, K. Coventry, V. Edmondson, and E. Dias, "Crumb rubber used in concrete to provide freeze-thaw protection (optimal particle size)," Journal of Cleaner Production, vol. 112, pp. 599-606, 2016.

[3] M. Jin, L. Jiang, M. Lu, N. Xu, and Q. Zhu, "Characterization of internal damage of concrete subjected to freeze-thaw cycles by electrochemical impedance spectroscopy," Construction and Building Materials, vol. 152, pp. 702-707, 2017.

[4] M. Nili, A. Azarioon, and S. M. Hosseinian, "Novel internaldeterioration model of concrete exposed to freeze-thaw cycles," Journal of Materials in Civil Engineering, vol. 29, no. 9, article 04017132, 2017.

[5] M. Otieno, J. Ikotun, and Y. Ballim, "Experimental investigations on the influence of cover depth and concrete quality on time to cover cracking due to carbonation-induced corrosion of steel in RC structures in an urban, inland environment," Construction and Building Materials, vol. 198, pp. 172-181, 2019. 
[6] J. Geng and J. Sun, "Characteristics of the carbonation resistance of recycled fine aggregate concrete," Construction and Building Materials, vol. 49, pp. 814-820, 2013.

[7] E. Rozière, A. Loukili, and F. Cussigh, "A performance based approach for durability of concrete exposed to carbonation," Construction and Building Materials, vol. 23, no. 1, pp. 190199, 2009.

[8] Y. Wang, M. An, Z. Yu, S. Han, and W.-Y. Ji, "Durability of reactive powder concrete under chloride-salt freeze-thaw cycling," Materials and Structures, vol. 50, no. 1, p. 18, 2017.

[9] X. Chen, H. Q. Yang, S. H. Zhou, and Z. H. Wang, "Research on concrete freezing and thawing durability and characteristic parameters of bubbles," Journal of Building Materials, vol. 14, no. 2, pp. 257-262, 2011.

[10] S. W. Tang, E. Chen, Z. J. Li, and H. Y. Shao, “Assessment of steady state diffusion of volatile organic compounds in unsaturated building materials based on fractal diffusion model," Building and Environment, vol. 84, pp. 221-227, 2015.

[11] H. Kuosa, R. M. Ferreira, E. Holt, M. Leivo, and E. Vesikari, "Effect of coupled deterioration by freeze-thaw, carbonation and chlorides on concrete service life," Cement and Concrete Composites, vol. 47, pp. 32-40, 2014.

[12] M. Rao, M. Li, H. Yang, X. Li, and Y. Dong, "Effects of carbonation and freeze-thaw cycles on microstructure of concrete," Journal of Wuhan University of TechnologyMaterials Science Edition, vol. 31, no. 5, pp. 1018-1025, 2016.

[13] J. G. Niu, L. Yan, and H. T. Zhai, "Study on the influence of freeze-thaw on the carbonation property of fly ash concrete," Applied Mechanics and Materials, vol. 357-360, pp. 939-943, 2013.

[14] Z. He, S. W. Tang, G. S. Zhao, and E. Chen, "Comparison of three and one dimensional attacks of freeze-thaw and carbonation for concrete samples," Construction and Building Materials, vol. 127, pp. 596-606, 2016.

[15] Y. Cheng, Y. Zhang, Y. Jiao, and J. Yang, "Quantitative analysis of concrete property under effects of crack, freezethaw and carbonation," Construction and Building Materials, vol. 129, pp. 106-115, 2016.

[16] M. Kim, Y. J. Kwon, S. J. Choi et al., "A study on the properties of high volume fly-ash concrete according to the replacement method and ratio of fly-ash," Architectural Institute of Korea Structural Journal, vol. 18, no. 2, pp. 123-130, 2002.

[17] K. Ishimaru, H. Mizuguchi, C. Hashimoto, T. Ueda, K. Fujita, and M. Ohmi, "Properties of concrete using copper slag and second Class fly ash as a part of fine aggregate," Journal of the Society of Materials Science, Japan, vol. 54, no. 8, pp. 828-833, 2005.

[18] R. Siddique, "Effect of fine aggregate replacement with Class F fly ash on the abrasion resistance of concrete," Cement and Concrete Research, vol. 33, no. 11, pp. 1877-1881, 2003.

[19] A. D. Pofale and S. V. Deo, "Comparative long term study of concrete mix design procedure for fine aggregate replacement with fly ash by minimum voids method and maximum density method," KSCE Journal of Civil Engineering, vol. 14, no. 5, pp. 759-764, 2010.

[20] E. Kawano, K. Takasu, H. Koyamada et al., "Study on creep property of the concrete with high volume fly ash as a part of fine aggregate," in Proceedings of the Summaries of Technical Papers of Meeting, Architectural Institute of Japan, Tokyo, Japan, June 2015.

[21] S. Dueramae, W. Tangchirapat, and C. Jaturapitakkul, "Strength and heat generation of concrete using carbide lime and fly ash as a new cementitious material without Portland cement," Advanced Powder Technology, vol. 29, no. 3, pp. 672-681, 2018.

[22] S.-L. Pei, S.-Y. Pan, X. Gao, Y.-K. Fang, and P.-C. Chiang, "Efficacy of carbonated petroleum coke fly ash as supplementary cementitious materials in cement mortars," Journal of Cleaner Production, vol. 180, pp. 689-697, 2018.

[23] T. Seo, M. Lee, C. Choi, and Y. Ohno, "Properties of drying shrinkage cracking of concrete containing fly ash as partial replacement of fine aggregate," Magazine of Concrete Research, vol. 62, no. 6, pp. 427-433, 2010.

[24] H. Mihashi, "Characteristic points of AIJ recommendations for practice of crack control in reinforced concrete buildings (design and construction)," Concrete Journal, vol. 45, no. 2, pp. 9-15, 2007.

[25] T. Bilir, O. Gencel, and I. B. Topcu, "Properties of mortars with fly ash as fine aggregate," Construction and Building Materials, vol. 93, pp. 782-789, 2015.

[26] T. Bilir, I. Yüksel, I. B. Topcu, and O. Gencel, "Effects of bottom ash and granulated blast furnace slag as fine aggregate on abrasion resistance of concrete," Science and Engineering of Composite Materials, vol. 24, no. 2, pp. 261-269, 2017.

[27] I. Tekin, M. Yasin Durgun, O. Gencel, T. Bilir, W. Brostow, and H. E. Hagg Lobland, "Concretes with synthetic aggregates for sustainability," Construction and Building Materials, vol. 133, pp. 425-432, 2017.

[28] F. U. A. Shaikh and S. W. M. Supit, "Compressive strength and durability properties of high volume fly ash (HVFA) concretes containing ultrafine fly ash (UFFA)," Construction and Building Materials, vol. 82, pp. 192-205, 2015.

[29] B. L. D. S. Costa, J. C. D. O. Freitas, P. H. S. Santos, D. M. D. A. Melo, R. G. D. S. Araujo, and Y. H. D. Oliveira, "Carbonation in oil well Portland cement: influence of hydration time prior to contact with $\mathrm{CO}_{2}$," Construction and Building Materials, vol. 159, pp. 252-260, 2018.

[30] S. Monkman, P. A. Kenward, G. Dipple, M. MacDonald, and M. Raudsepp, "Activation of cement hydration with carbon dioxide," Journal of Sustainable Cement-Based Materials, vol. 7 , no. 3, pp. 160-181, 2018.

[31] D. Nair, "Fly ash as a fine aggregate replacement in concrete building blocks," International Journal of Engineering and Advanced Research Technology, vol. 2, no. 1, pp. 47-51, 2015.

[32] M. Uma Maguesvari and T. Sundararajan, "Influence of fly ash and fine aggregates on the characteristics of pervious concrete," International Journal of Applied Engineering Research, vol. 12, no. 8, pp. 1598-1609, 2017.

[33] M. Ming-Jie, Z. Dong-Sheng, Y. Qiuning, and Z. Wenbo, "Study of durability of concrete with fly ash as fine aggregate under alternative interactions of freeze-thaw and carbonation," Advances in Civil Engineering, vol. 2019, Article ID 4693893, 15 pages, 2019.

[34] Y. Chen, G. Cen, and Y. Cui, "Comparative study on the effect of synthetic fiber on the preparation and durability of airport pavement concrete," Construction and Building Materials, vol. 184, pp. 34-44, 2018.

[35] C. Yun-Hong, C. Dong-Hua, and W. Yuan, "Relationship between cement content and frost resistance of concrete," Journal of Building Materials, vol. 14, no. 4, pp. 536-531, 2011.

[36] N. Li, G. Long, Q. Fu, X. Wang, K. Ma, and Y. Xie, "Effects of freeze and cyclic flexural load on mechanical evolution of filling layer self-compacting concrete," Construction and Building Materials, vol. 200, pp. 198-208, 2019.

[37] Z. Hu, H. Ding, J. Lai, H. Wang, X. Wang, and S. He, "The durability of shotcrete in cold region tunnel: a review," 
Construction and Building Materials, vol. 185, pp. 670-683, 2018.

[38] Z. Li, Advanced Concrete Technology, John Wiley \& Sons, Hoboken, NJ, USA, 2011.

[39] C. Li, L. Jiang, N. Xu, and S. Jiang, "Pore structure and permeability of concrete with high volume of limestone powder addition," Powder Technology, vol. 338, pp. 416-424, 2018.

[40] L. Basheer, J. Kropp, and D. J. Cleland, "Assessment of the durability of concrete from its permeation properties: a review," Construction and Building Materials, vol. 15, no. 2-3, pp. 93-103, 2001.

[41] P. F. Marques, C. Chastre, and Â Nunes, "Carbonation service life modelling of RC structures for concrete with Portland and blended cements," Cement and Concrete Composites, vol. 37, no. 3, pp. 171-184, 2013.

[42] B. Li, L. Zhang, J. Wei, and Y. Ren, "Pore damage properties and permeability change of coal caused by freeze-thaw action of liquid nitrogen," Advances in Civil Engineering, vol. 2018, Article ID 5076391, 9 pages, 2018.

[43] D. Niu, Q. Xiao, and W. Zhu, "Concrete damage and neutralization under coupling effect of carbonation and freezethaw cycles," Journal of Wuhan University of TechnologyMaterials Science Edition, vol. 27, no. 2, pp. 353-357, 2012.

[44] C. Zhu, Y. Fang, and H. Wei, "Carbonation-cementation of recycled hardened cement paste powder," Construction and Building Materials, vol. 192, pp. 224-232, 2018.

[45] C. Grengg, B. Müller, C. Staudinger et al., "High-resolution optical $\mathrm{pH}$ imaging of concrete exposed to chemically corrosive environments," Cement and Concrete Research, vol. 116, pp. 231-237, 2019.

[46] R. S. Teixeira, G. H. D. Tonoli, S. F. Santos et al., "Nanoindentation study of the interfacial zone between cellulose fiber and cement matrix in extruded composites," Cement and Concrete Composites, vol. 85, pp. 1-8, 2018.

[47] W. Gu, F. Xu, S. Wang, W. Li, and Y. Tan, "Effect of fly ash content on the carbonization resistance of cement paste," IOP Conference Series: Earth and Environmental Science, vol. 153, no. 5, article 052042, 2018.

[48] V. G. Papadakis, C. G. Vayenas, and M. N. Fardis, "Fundamental modeling and experimental investigation of concrete carbonation," Materials Journal, vol. 88, no. 4, pp. 363-373, 1991.

[49] Z. Yu and L. Jiang, "A practical mathematical model of concrete carbonation depth based on the mechanism," Industrial Construction, vol. 28, pp. 16-19, 1998.

[50] K. Zhang and J. Xiao, "Prediction model of carbonation depth for recycled aggregate concrete," Cement and Concrete Composites, vol. 88, pp. 86-99, 2018.

[51] C. Jiang, X. Gu, Q. Huang, and W. Zhang, "Carbonation depth predictions in concrete bridges under changing climate conditions and increasing traffic loads," Cement and Concrete Composites, vol. 93, pp. 140-154, 2018.

[52] P. Zhu, K. Chen, and K. Hu, "Carbonation behavior of repeated recycled fine aggregate concrete under bending load," KSCE Journal of Civil Engineering, vol. 23, no. 2, pp. 729-736, 2019.

[53] Y. Qi, N. Di-Tao, Y. Cheng-Fang, and Q. Feng, "Experimental study on concrete carbonation depth in freezing-thawing circumstance," Bulletin of the Chinese Ceramic Society, vol. 31, no. 4, pp. 979-983, 2012. 


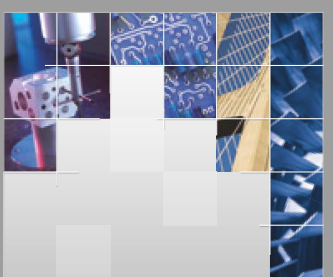

\section{Enfincering}
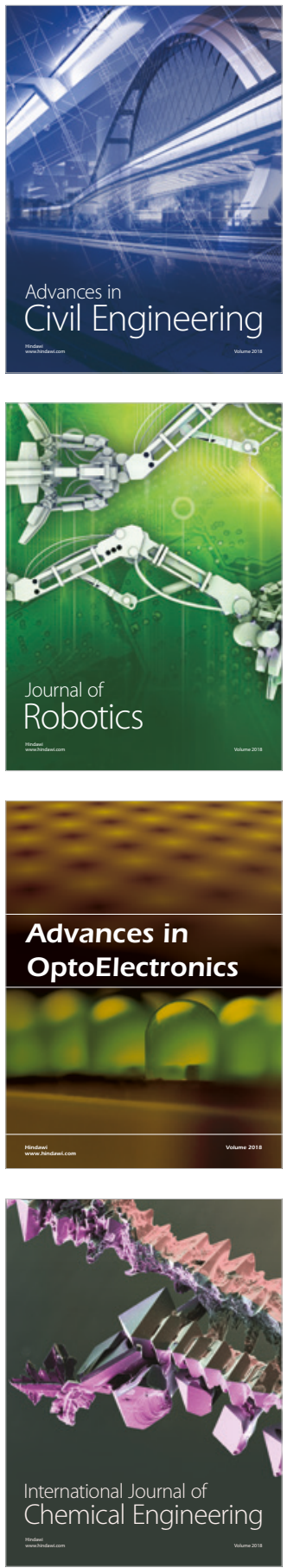

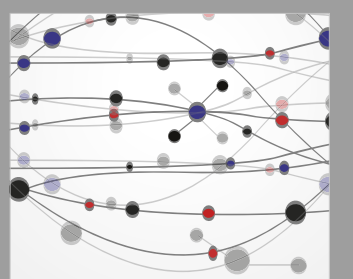

\section{Rotating \\ Machinery}

The Scientific World Journal

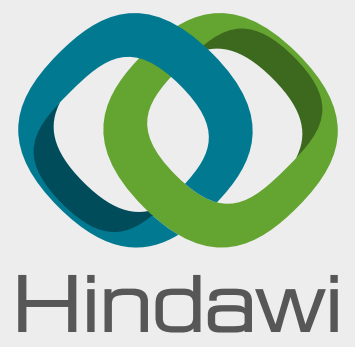

Submit your manuscripts at

www.hindawi.com
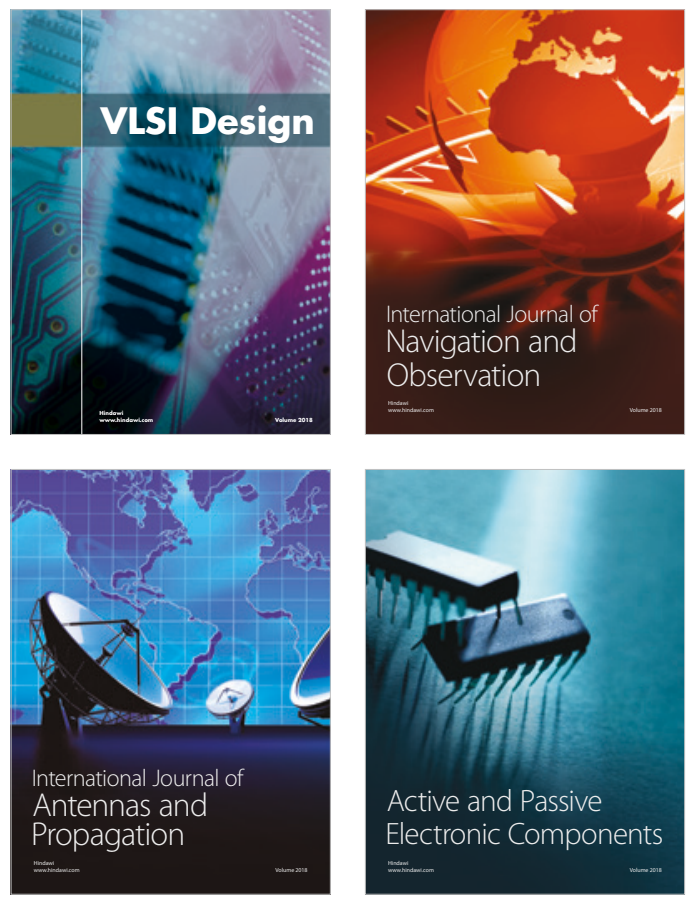
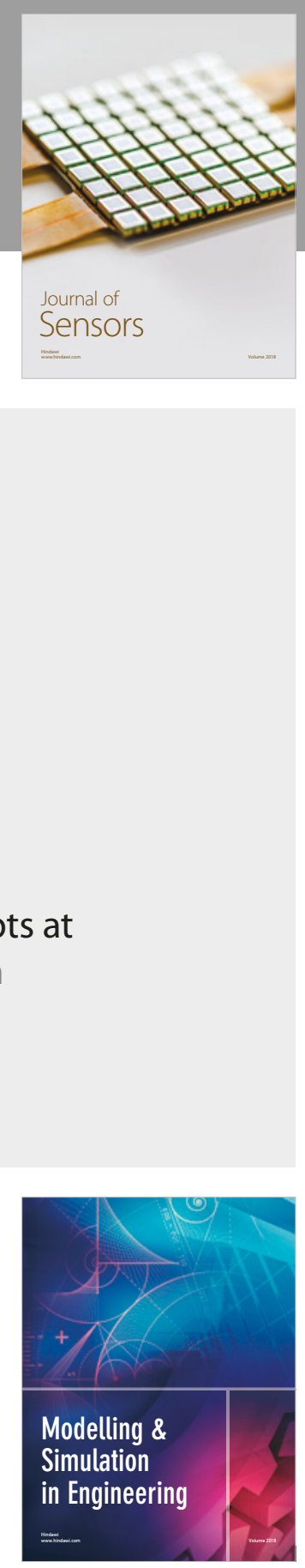

\section{Advances \\ Multimedia}
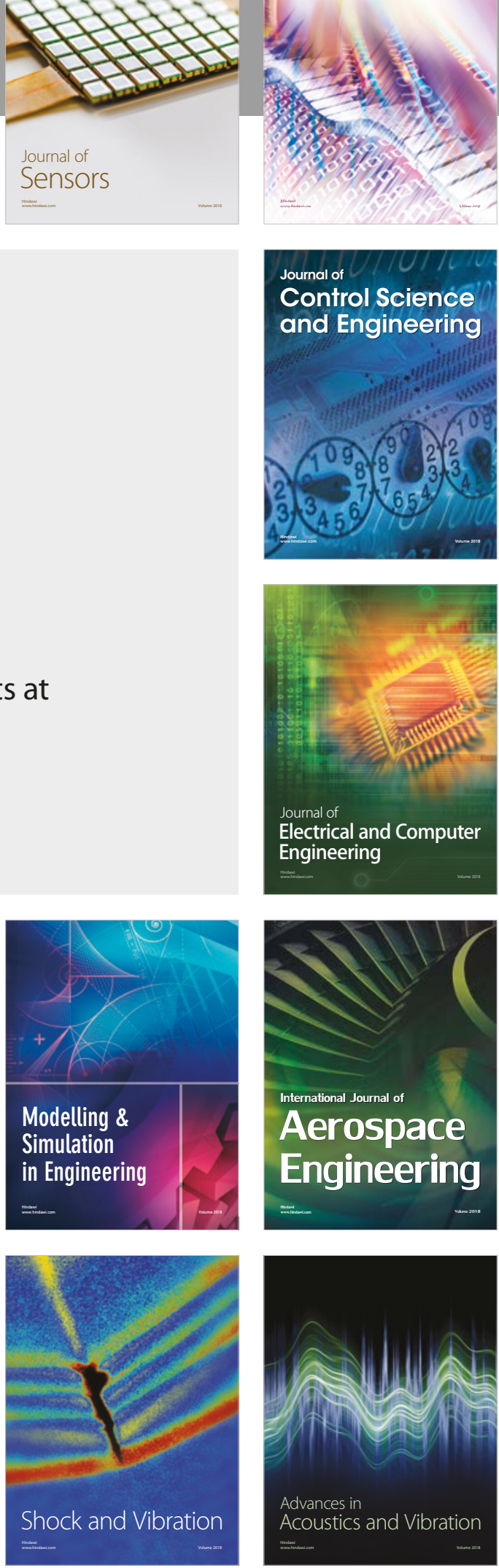